\title{
Diabetic Nephropathy Prevention and the Role of Managed Care Pharmacists
}

\author{
Brian Hinsey \\ and Grover C. Lee
}

\section{OBJECTIVE:}

To demonstrate the practical value of the managed care pharmacist in drug selection. The managed care pharmacist can provide valid scientific data to the physician that will turn aid in appropriate drug selection for each patient as an individual.

\section{DATA SOURCES:}

Scientific journals and texts.

\section{STUDY SELECTION:}

Not applicable.

\section{DATA EXTRACTION:}

Not applicable.

\section{DATA SYNTHESIS:}

Managed care activities are receiving increased publicity, most of which is negative in nature. Managed care pharmacists can generate a refreshingly positive demonstration of managed care. Their usefulness in drug selection can be effective whether care is concurrent, retrospective or prospective. Managed care pharmacists can use drug use data, disease state, and therapy knowledge to make a positive impact on how drugs are selected. Each patient is an individual with his or her own set of risks and experiences. Barriers are present to true participation in drug selection responsibilities but pharmacists can offer viable unbaised information on new drugs and drug selection.

\section{CONCLUSION:}

Prevention of diabetes complications, namely diabetic nephropathy, has a role for the managed care pharmacist. The intervention by the pharmacist can potentially improve therapy as well as prevent other drug therapies that would be needed as the diabetic kidney fails leading to end stage renal disease. This intervention to better therapy has a dual benefit. The more expensive and inappropriate calcium antagonist used in patients with diabetes can be exchanged for better therapy in the ACE inhibitors, which is also much less expensive. Pharmacists need only to take the initiative and make an effort to promote "good therapy."

\section{KEY WORDS:}

Diabetic nephropathy, Managed care, ACE inhibitors, Calcium channel blockers, Disease management

J Managed Care Pharm 1997; 3:682-687
Diabetic nephropathy is the leading cause of end-stage renal disease (ESRD) in the United States. Diabetic nephropathy affects about $40 \%$ of patients with type I diabetes who have had diabetes for 20 years or more and $4 \%-20 \%$ of patients with type Il diabetes.' According to Bakris and Stein, ${ }^{2} 35 \%$ of all patients with diabetes will develop diabetic nephropathy sometime during their lifetime. Clearly, it is important to recognize the earliest stages of diabetic nephropathy, namely the detection of microalbuminuria, and start appropriate therapy. ${ }^{1}$ Clinical studies ${ }^{2.31}$ have looked at calcium antagonists and $\mathrm{ACE}$ inhibitors as possible agents to treat, as well as prevent, diabetic nephropathy. This article will discuss and compare these two drug classes in terms of their roles in treating and preventing diabetic nephropathy

\section{PATHOPHYSIOLOGY}

Diabetes affects the kidneys in many ways; diabetic nephropathy encompasses all the structure changes, i.e., lesions within the kidney and the changes in kidney functioning such as renal blood flow (RBF) regulation and glomerular filtration rate (GFR) as measured by creatinine clearance $(\mathrm{CrCl})$.

At the onset of type I diabetes, RBF and GFR generally are elevated with no apparent histological abnormalities. Glycemic control is a major determining factor in the time required to produce histological changes such as glomerular basement membrane thickening and increased mesangial matrix material build-up. These two changes also cause renal

\section{$\Delta \quad$ Authors} BRIAN HINSEY, PHARM.D, is Assistant Director of Clinical Pharmacy; and GROVER C. LEE is PresidenuCEO of American Health Care
Administrative Services, Inc., Roseville, CA. Autror CORRESPONDENCE: Brian Hinsey, Assistant Director of Clinical Pharmacy, American Health Care Administrative Services, Inc., 3001 Douglas
Boulevard, Suite 210, Rosevilie, CA 95661. 
hypertrophy. Progressive histological damage may continue over about a 10-year period and lead to renal hyperfiltration. The persistent increase in filtration rate leads to an increase in intraglomerular capillary pressure; the initial build-up of glomerular material causes a subsequent morphological change in kidney size. This hypertrophic stage is slowly reversed due to the constant pressure on the filtering system. The damage caused by renal hyperfiltration with increased intraglomerular capillary pressure slowly causes irreversible damage to the kidney nephron cells, to a point where the kidneys start to lose form and function. These histological changes are grossly manifested as a reduction in kidney size from hypertrophy to atrophy. DeFronzo' has estimated that it may take approximately 10 years to progress to kidney hypertrophy and another 15 years to kidney atrophy. Some time during this 15 years albuminuria is detected through a laboratory test used to indicate the first signs of kidney damage. Eventually, the elevated RBF and GFR return to normal. This last sign indicates the point of no return in preventing the onset and progression of ESRD.' The constant pressure on the mesangial matrix, along with hyperfiltration, eventually causes the deterioration of the filtering membranes and destruction of both kidney function and tissue. Development of microalbuminuria may take 20-25 years. Anderson et al. ${ }^{3}$ give a time line of $6-9$ years, but this may not represent the years diabetes went undiagnosed. Other nonhistological changes include an increase in sodium $(\mathrm{Na})$ retention by the kidney and increased vascular reactivity in the presence of vasoconstrictors such as norepinephrine and angiotensin-II. Also noted at this time is the absence of myogenic reflex control of efferent arteriolar tone and subsequent blood flow into the glomerular capillaries. ${ }^{2}$

The onset of microalbuminuria ( $30-300 \mathrm{mg} / 24 \mathrm{hr}$ ) is the point at which drug therapy is started by most physicians, but this critical danger sign often is not detected because it is not routinely measured. Urine dipsticks detect gross protein measurements called macroproteinuria ( $>300 \mathrm{mg} / 24 \mathrm{hr}$ ). Microalbuminuria and macroproteinuria should not be compared for this measurable difference because the disease process is more advanced with the presence of macroproteinuria. ${ }^{4}$ Tight glycemic control (i.e., maintenance of postprandial glucose less than $140 \mathrm{mg} / \mathrm{dL}$ ), may prevent the onset of microalbuminuria. ${ }^{5.6}$ The Diabetes Control and Complication Trial ${ }^{7}$ showed that tight glycemic control vs. conventional control had no significant effect on the progression of existing microalbuminuria. Risk factors for development of diabetic nephropathy include a family history of cardiovascular disease, ${ }^{8}$ a history of $\mathrm{HbA}_{1 \mathrm{c}}>9.5,{ }^{9}$ and the presence of microalbuminuria.

Insulin-dependent diabetes mellitus (IDDM) patients with microalbuminuria that progresses to clinical proteinuria have a cardiovascular disease mortality rate that is 37 times higher than the general population..$^{10,11}$ Jensen et al. ${ }^{12}$ showed that blood pressure did not correlate with the presence or absence of microalbuminuria. This indicates that hypertension (HTN) is a consequence and not a cause of diabetic renal disease. However, hypertension is an important factor in the progression of renal disease. ${ }^{13}$

The pathologic hallmark of diabetic renal disease is mesangial matrix expansion with thickened glomerular basement mem- brane. However, about one in five IDDM patients without hypertension or microalbuminuria have mesangial matrix expansion. This may indicate that progression to diabetic nephropathy can occur in the absence of clinical signs and symptoms. ${ }^{14}$ The duration of diabetes correlates poorly with the degree of mesangial matrix expansion; ${ }^{15,16}$ however, this is only an indirect factor if glycemic control is poor.

Angiotensin-II, endothelin, and vasopressin are all associated with mesangial cell proliferation and matrix expansion. Angiotensin-II is the primary problem in the pathophysiologic progression of diabetic nephropathy. ${ }^{17,18}$

\section{TREATMENT WITH CALCIUM ANTAGONISTS}

Intracellular calcium concentrations are elevated in the hypertensive patient. This, in turn, leads to an increase in vasoconstriction responsiveness to vasoactive hormones such as angiotensin-Il and norepinephrine in vascular smooth muscle and mesangial cells. This pathophysiologic abnormality provides the rationale for the use of calcium antagonists. If the calcium is blocked, its effects on angiotensin-II also are eliminated. Unfortunately, not all of the calcium antagonists work. For instance, Hill et al. ${ }^{19}$ offered evidence suggesting that more than an increase in cystolic calcium is responsible for cell proliferation

The dihydropyridines-class calcium antagonists do not appear to be consistent in their ability to preserve renal function. Dihydropyridines may increase renin secretion which, in turn, increases angiotensin-Il production, leading to continued expansion of mesangial matrix. ${ }^{20}$ Also, the lack of dihydropyridine calcium channels on the efferent arteriole leads to a more pronounced effect of angiotensin-II. ${ }^{21}$ This effect causes an increase in GFR, as well as an increase in urinary albumin excretion (UAE) ${ }^{22-24}$ The dihydropyridine lack of protection against diabetic nephropathy development is evidenced again by the total lack of effect on glomerulosclerosis, a precursor to diabetic nephropathy. ${ }^{25-27}$ Nicardipine, which has a side chain in its chemical structure that is similar to the verapamil configuration, may be an exception. More studies are needed to verify the effectiveness of nicardipine. ${ }^{28,29}$

Verapamil and diltiazem are the only calcium antagonists with definitive proof of renal preservation effects; several studies document the renal hemodynamics of these compounds. For example, Raij et al. ${ }^{30}$ demonstrated a decrease in mesangial uptake of macromolecules due to a decreased mesangial membrane permeability and pore size. Several studies ${ }^{31-33}$ also indicate that the mechanism(s) responsible for autoregulation of renal blood flow are inhibited by calcium antagonists. Verapamil and diltiazem have been shown to effectively decrease UAE in several studies..$^{30.34 .35}$ This result was due to a decrease in intraglomerular volume rather than intraglomerular pressure ${ }^{36}$ Mesangial matrix expansion is decreased ${ }^{37-39}$ due to the predominant mechanism of action afforded to calcium antagonists. This calcium channel blockage decreases the effects of angiotensin-Il which, in turn, reduces the cell proliferation of 
mesangial cells. Lastly, verapamil and diltiazem were shown to slow the progression of glomerulosclerosis. ${ }^{39.40}$

Only verapamil and diltiazem calcium channel blockers blunt the intrarenal efferent arteriolar effects of angiotensinII. ${ }^{+1}$ Verapamil and diltiazem seem to be about as effective as the ACE inhibitors in patients with both diabetes and hypertension. Studies with normotensive patients are less clear in the practical use of calcium antagonists.

\section{TREATMENT WITH ACE INHIBITORS}

Angiotensin Converting Enzyme (ACE) inhibitors have been accepted as the "gold standard" for the treatment of diabetic kidney disease. However, the antiproteinuric response to ACE inhibitors is not uniform. About $60 \%$ of diabetic patients respond with a reduction in microproteinuria and proteinuria, whereas the remaining $40 \%$ do not respond at all. ${ }^{42}$

A decrease in serum albumin levels is an indication that albumin is being lost. Normal serum albumin levels are approximately $3.5-5.5 \mathrm{~g} / \mathrm{dL}$. Praga et al. ${ }^{43}$ showed that patients with serum albumin levels of $3.5 \mathrm{~g} / \mathrm{dL}$ or higher had an average reduction in protein excretion of about $50 \%$, whereas patients with serum albumin levels of 3.0 or less did not respond. This suggests that the number of patients responding to ACE inhibitors is probably greater than $60 \%$ if treatment is started within the first few months after microalbuminuria is detected. There is also increased interest in using ACE inhibitors early in the course of renal disease. Starting an ACE inhibitor before the development of overt nephropathy whose first sign is the presence of microalbuminuria has much support. ${ }^{44,45}$

Materson ${ }^{46}$ points out that diabetologists seem to be treating a majority of their patients with ACE inhibitors, although it remains unclear whether or not all types of diabetes should be treated with these compounds. Ravid et al. ${ }^{47}$ proved that the antiproteinuric effect of ACE inhibitors is beneficial in normotensive diabetics as well. Blood pressure reduction in normotensive diabetics has been minor. Two studies $5^{48,49}$ have concluded that the ACE inhibitors' renal effects are independent of blood pressure reduction. The renal hemodynamics of ACE inhibitors have been shown to be due to their selective effects on efferent arteriole resistance. This consequently decreases intraglomerular pressure, as well as slows the diabetic renal disease process to an extent greater than simple blood pressure control alone. ${ }^{50,51}$

Two studies by DeFronzo ${ }^{52.53}$ have shown that ACE inhibitors decrease peripheral vascular resistance by inhibiting the production of angiotensin-II. GFR also is relatively unaffected, whereas RBF is increased and the filtration fraction is decreased. These studies also showed that ACE inhibitors decrease proteinuria and microalbuminuria. However, ACE inhibitors also decrease mesangial matrix expansion. This is probably due to the direct effects on angiotensin-II.

Other beneficial effects of ACE inhibitors, which are seen in most of the calcium antagonists, include increased insulin sensitivity, lack of affect on blood glucose, and effectiveness in treating dyslipidemia. ${ }^{54,55} \mathrm{Hirsh}^{56}$ points out that even low levels of microalbuminuria worsens dyslipidemia and that albumin is directly toxic to renal cells.

Materson ${ }^{46}$ suggests that the renoprotective effect of ACE inhibitors is generalizable to patients with diabetes. However, there have been preliminary data on specific tissue-level ACE inhibition activity that shows differences among the ACE inhibitors. Further research is needed to clarify this issue. ${ }^{57}$

\section{COMPARISON OF ACE INHIBITORS TO CALCIUM ANTAGONISTS}

Studies ${ }^{2 \cdot 31}$ have shown verapamil and diltiazem are equivalent to ACE inhibitors. Combination therapy using both a calcium antagonist and an ACE inhibitor has a synergistic reduction in UAE. However, even with long-term treatment, research has shown no significance for multiple drug therapy in slowing of the disease process. ${ }^{58}$

\section{DISCUSSION}

Many published clinical trials indicate that an ACE inhibitor should be a drug of choice in diabetic patients for treatment and/or prevention of diabetic nephropathy. ${ }^{2-31} \mathrm{An}$ ACE inhibitor should be started when microalbuminuria is detected. ${ }^{44.45}$ ACE inhibitor use in diabetic patients that have high risk for the development of diabetic nephropathy also is beneficial.

Physicians should still monitor for microalbuminuria on an annual basis. At greatest risk are those patients who have a 10-year-or-longer history of diabetes, a significant history of poor glycemic control demonstrated by a consistent $\mathrm{HbA}_{1 \mathrm{c}}>$ 9.5, a family history of cardiovascular disease, and an elevated $\mathrm{CrCL}$ of $>120 \mathrm{cc} / \mathrm{min}$.

Clinical and laboratory results are not routinely available to pharmacists. However, managed care pharmacists can easily identify diabetic patients by insulin and/or oral hypoglycemic use. With a routine review of the patients profile, they can make a determination of possible hypertension and help improve treatment. For example, if the patient is not on an ACE inhibitor, the pharmacist might suggest this course of treatment to the physician. If the ACE inhibitor fails, denoted by development or worsening of increased urinary albumin excretion, a calcium antagonist of either verapamil or diltiazem class can be used. Nicardipine is not recommended as an alternative choice by the authors at this time.

The cost of drug therapy for all patients with ciabetes is minor compared to the cost of treatment for diabetic nephropathy. If drug cost is a major budget concern, the number of patients with diabetes can be reduced by first treating high risk patients. Additional savings result from the differences in cost of an ACE inhibitor and calcium antagonist. Proper treatment may reduce or reverse the progression of kidney damage in high-risk patients and enable them to live a healthier life for years. 


\section{PHARMACOECONOMICS}

Based on 1990 statistics, ${ }^{\mathrm{B} 3}$ there were 13 million diabetic patients in the U.S. (5.2\% of the general population), of which half have not been properly diagnosed. The occurrence of ESRD is stated to be in the range of $4 \%^{88}$ to $21 \%{ }^{89}$ of all diabetics. Thus, for a population of 100,000 , there are approximately 5,200 patients with diabetes; of these, 208-1,092 will develop ESRD requiring dialysis.

The direct cost of dialysis is $\$ 150$ per treatment, and most patients require treatment 13 times a month. ${ }^{90}$ Additional costs include $\$ 2,500$ to $\$ 13,000$ per year for transportation to and from appointments, ${ }^{91} \$ 6,300$ per year for auxillary medications and dietary supplements, ${ }^{91} \$ 1,750$ in supplies for proper control for the year (insulin, oral medications, syringes, testing equipment), ${ }^{92}$ and an undefined number of monthly doctor's office appointments at approximately $\$ 45$ per visit every month. The total direct cost to the health care system is between $\$ 34,490$ and $\$ 44,990$ per patient per year.

Indirect costs essentially involve the lost work time due to medical appointments. As $65 \%$ of dialysis patients are gainfully employed, ${ }^{92}$ this lost time results in a $\$ 5,000-\$ 7,500$ loss of income annually, per patient. Another indirect cost is the pharmacist's intervention in identifying a diabetic patient at risk for ESRD. Total indirect costs equal $\$ 5,180-\$ 7,680$ per patient per year.

Since the use of dihydropyridine-class calcium channel blockers to prevent ESRD in patients with diabetes has been shown to be ineffective, the question arises whether to treat all diabetics or diabetic patients who also have comorbid cardiovascular disease(s). This question can be answered with a cost-benefit analysis (CBA).

A benefit per patient treated with an ACE inhibitor for prevention equals the dialysis costs that are not spent $(\$ 39,670$ to $\$ 52,670)$. The cost should include the continued use of supplies to control diabetes $(\$ 1,750)$, the cost of the ACE inhibitor at $\$ 360$ per year, plus the potential reimbursement to the managed care pharmacist of $\$ 1.5$ for every fill of the ACE inhibitor ( $\$ 180$ for a 12 -month period). The total cost is $\$ 2,290$.

In most cases, the dollars are budgeted so a discount rate of $5 \%$ will be chosen. This reduces the benefit total to a range of $\$ 22,089$ to $\$ 29,328$. The costs are also reduced by $\$ 1,275$. The CBA results in a ratio of 17.3-23.0 to one, which means that for every dollar spent, the benefit gained is $\$ 17.30$ to $\$ 23.00$ for preventive treatment in a patient with diabetes who will go on to develop ESRD.

How do you determine which diabetic patients to treat and which not to treat? The total cost to treat all diabetic patients is estimated to be approximately $\$ 500$ per person per year; but when this cost is discounted due to extended payments, the cost is reduced to $\$ 300$ for ACE inhibitor and managed care pharmacist's cognitive service fee. The remaining $\$ 975$ in direct and indirect cost is for treating diabetes. For a population of 100,000 lives, one would expect 5,200 diabetic patients, of which a minimum of 208 may require dialysis for ESRD.

The CBA for this 100,000-patient population would have a benefit of $208 \times(\$ 22,089-\$ 975)=\$ 4,391,712$ and a cost of $5,200 \times \$ 300=\$ 1,560,000$ resulting in a ratio of $2.8: 1$. This means that at the most conservative estimates the costs only marginally warrant treating all patients with diabetes. According to Health Watch, ${ }^{94}$ hypertension affects $60 \%-65 \%$ of all patients with diabetes. If just those patients with diabetes and hypertension are treated, the cost is reduced to $\$ 936,000$ $\$ 1,014,000$. The CBA ratio then becomes 4.3:4.6. Depending on the number of patients with diabetes, budget considerations, and available time to implement a pharmacist intervention program, one can justify intervening for all patients with. diabetes. At a minimum, intervening on behalf of patients with both diabetes and hypertension is warranted.

\section{CONCLUSION}

The managed care pharmacist can take an active role in assisting the physician by implementing protocols or screens that assess diabetic patients' drug profiles. Diabetic patients that are taking a dihydropyridine calcium antagonist should be targeted. By identifying the patients with diabetes and confirming the diagnosis of hypertension, the managed care pharmacist may intervene not only to save money but also to improve therapy with the substitution of an ACE inhibitor. Ideally, if pharmacists could identify only those patients that will develop diabetic nephropathy leading to ESRD, the cost benefit is more than $\$ 17$ saved for every $\$ 1$ spent. However, this is not feasible. By treating all patients with diabetes to prevent renal problems, the CBA is $\$ 2.80$ benefit per dollar spent. A second option is to treat just those patients with both diabetes and hypertension; the CBA here increases to $\$ 4.30$ to $\$ 4.60$ saved for every dollar spent. Renal diseases in patients with diabetes can be prevented and should be prevented with intervention from a pharmacist.

\section{A References}

1. DeFronzo RA. Nephropathy. In: Lebovitz, ed.Therapy for Diabetes Mellitus and Related Disorders. Alexandria, VA: American Diabetes Association 1.994: 256-65.

2. Bakris Gl., Stein JH. Diabetic Nephropathy. Disease-A-Month 1993; 39(8): 573-611
3. Anderson AK, Christensen JS, Anderson JK, et al. Diabetic Nephropathy in Type I diabetes: An Epidemiological study. Diabetologia 1983; 25: 496-502. 4. Hirsch Irl B. Surveillance for complications of diabetics: don't wait for symptoms before intervening. Postgraduate Med 1996; 99(3): 147-150,153-155, 159-162.

5. Rosenstock J, Raskin P. Relationship of Diabetic
Nephropathy to Glycemic Control. In: Brenner BM, Stein JH, eds. The kidney in diabetes mellitus. Vol 20. New York, NY; Churchill Livingston; 1989: 1-18. 6. Viberti GC, Bilous RW, Mackintosh B, et al. Long-term correction of hyperglycemia and progression of renal failure in insulin dependent diabetes. BMJ 1983; 286: 598-602.

7. The Diabetes Control and Complications (DC- 
CT) Research Group. Effect of intensive therapy on the development and progression of diabetic nephropathy in the DCCT. Kidney Int 1995; 47(6): 1703-1720.

8. Earle $K$, Walker J, Hill C, Viberti GC. Familial clustering of cardiovascular disease in patients with insulin dependent diabetics and nephropathy. NEJM 1992; 326: 673-677

9. Wisemann MJ, Mangila R, Alberretı M, el al. Glomerular response mechanisms to glycemic changes in insulin dependent diabetes. Kidney Int 1987; 31: 1012-1018

10. Borch-Johnsen K. Incidence of nephropathy in insulin dependent diabetes as related to mortality. In: Mogensin CE, ed. The kidney and hypertension in diabetes mellitus. Boston, MA Martinus Nijhoff; I988: 33-54.

11. Damsgaad EM, Froland A, Mogensen CE. Microalbuminuria is a strong predictor of 6 -yr mortality of elderly noninsulin dependent diabetes and nondiabetics: a prospective study [abstract]. Diabetologia 1.988; 31: 483a

12. Jensen $T$, Borch-Johnsen K, Deckert $T$. Changes in blood pressure and renal function in patients with type 1 diabetes mellitus prior to clinical diabetic nephropathy. Diabetes Res 1.987 ; 4: 159-163.

13. Parving $\mathrm{H}-\mathrm{H}$, Anderson AR, Smidt F, et al. Effect of antihypertensive treatment on kidney function in diabetic nephropathy. BMJ 1987; 294:

1443-1445.

14. Chavers BM, Bilous RW, Ellis EN, et al. Glomerular lesions and urinary albumin excretion in Type 1 cliabetes without overt proteinuria. NEJM 1989; 320: 966-970.

15. Mauer SM, Steffes MW, Ellis EN, et al. structural-functional relationships in diabetic nephropathy. J Clin Invest 1984; 74: 1143-1.149. 16. Saito Y, Kida H, Takeda S, et al. Mesangiolysis in diabetic glomeruli: its role in the formation of nodular lesions. Kidney Int 1988; 34: 389-396. 17. Bakris GL, Re R. Endothelin modulates angiotensin-ii induced mitogenisis. Am J Physiol 1993.

18. Bakris GL. The effects of calcium antagonists on renal hemodynamics, urinary protein excretion, and glomerular morphology in diabetic states. J Am Soc Nephrol 1991; 2(suppl 1): 21-29. 19. Hill TD, Dean NM, Mordan LJ, et al. PDGFinduced activation of phospholipase $C$ is not required for induction of DNA-synthesis. Science 1990; 248: 1660-1663.

20. Bauer JH, Sunderrajan S, Reams G. Effects of calcium entry blockers on renin-angiotensin-aldosterone system renal function and hemodynamics, salt water excretion and body fluid composition. Am J Cardiol 1985; 56: 62H-67H 21. Carmines PK, Fowler BC, Bell PD. Direct evidence for voltage gated $\mathrm{Ca} 2+$ channels in afferent but not efferent arterioles from rabbit kidney labstract]. Am J Hypertens 1992; 5: 13

22. Sakurai'T, Kurita T, Nagano S, Sonada T. Antihypertensive vasodilating and sodium diuretic actions of $\mathrm{D}$-cis isomer of benzzothiazine derivative (CRD-401). Acta Urol Jpn 1972; 18: 695-701.

23. Van Schaik BAM, Van Nistelroog AE], Geyskes
GG. Antihypertensive and renal effects of nicardipine. Br J Clin Pharmacol 1984; 18: 57-63. 24. Yokoyana S, Kaburagi T. Clinical effects of intravenous nifedipine on renal function. J Cardiovasc Pharmacol 1983; 5: 67-71.

25. Anderson S, Rennke HG, Zayas MA, Brenner $B M$. Calcium channel blockade versus converting enzyme inhibition in experimental diabetes. Kidney Int 1992; 41: 891-7.

26. Rosenthal T, Rosenmann E, Cohen AM. Effects of nisoldipine on hypertension and glomerulosclerosis in Cohen diabetic rats with Goldblau hypertension [abstract]. Am J Hypertens 1990; 7: 27.

27. Jackson B, Johnston CI. The contribution of systemic hypertension to progression of chronic renal failure in the rat remnant kidney: effect of treatment with an angiotensin-converting enzyme inhibitor or calcium inhibitor. J Hypertens 1988 ; 6: 495-501.

28. Stornello M, Valvo E, Scapellato L. Hemodynamic, renal and humoral effects of the calcium entry blockers nicardipine and converting enzyme inhibitor captopril in hypertensive type I diabetic patients with nephropathy. J Cardiovasc Pharmacol 1989; 14:851-5

29. Baba T, Murabayashi S, Takebe K. Comparisons of the renal effects of angiotensin-converting enzyme inhibitor and calcium antagonists in hypertensive type II diabetic patients with microalbuminuria: a controlled trial. Diabetologia 1989; 32: $40-44$.

30. Raij L, Keane WF Glomerular Mesangium: its function and relationship to angiotensin-II. Am J Med 1985; 79(suppl 3c): 24-30

31. Loutzenhizer R, Epstein M, Horton C, Sonke $P$. Reversal by diltiazem of angiotensin-II induced renal vasoconstriction in the isolated perfused rat kidney [abstract]. Clin Res 1985; 33: 587a. 32. Ono H, Kokuban H, Hasimoto K. Abolition by calcium antagonists of the autoregulation of renal blood flow. Naungn Schmiedebergs Arch Pharmacol 1974; 285: 201-207

33. Steele TH, Chailoner-Hue L. Renal interactions between norepinephrine and calcium antagonists. Kidney Int 1984; 26: 719-724

34. Bakris GL. Effects of diltiazem or lisinopril on massive proteinuria associated with diabetes mellitus. Ann Int Med 1990; 112: 707-708.

35. Demarie BK, Bakris GL. Effects of different calcium antagonists on proteinuria associated with diabetes mellitus. Ann Int Med 1990; 113(1.2): 987-988.

36. Brown SA, Walton CL, Crawford P, Bakris GL. Long term effects of antihypertensive regimens on renal hemodynamics and proteinuria. Kidney Int 1993; 43: 1210-8

37. Scandling JD, Myers BD. Glomerular size selectivity and microalbuminuria in early diabetic glomerular disease. Kidney Int 1992; 41: 840-6. 38. Remuzzi A, Puntorieri S, Battaglia C, et al. Angiotensin converting enzyme inhibition ameliorates glomerular filtration of macromolecules and water lessens glomerular injury in the rat. $\mathrm{J}$ Clin Invest 1990; 85: 541-9.

39. Yoskioka T, Shiraga H, Yoshida Y, et al. Intact nephrons as the primary origin of proteinuria in chronic renal disease. J Clin Invest 1.988; 82 1614-23.

40. Gaber L, Walton C, Crawford P, Brown S Bakris GL. Converting enzyme inhibition or calcium antagonism alone or combined on histologic progression of diabetic nephropathy [abstract]. J Am Soc Nephrol 1992; 3: 332.

41. Carmines PK, Navar LG. Disparate effects of calcium channel blockade on afferent and efferent arteriolar responses to angiotensin-II. Ann J Physiol 1989; 256: F1015-20

42. Keilani T, Schueter WA, Batlle DC. Selected aspects of ACE inhibition therapy for patients with renal disease: Impact on proteinuria, lipids, and potassium. J Clin Pharmacol 1995; 35: 87-97.

43. Praga M, Borstein B, Andres A, et al. Nephrotic proteinuria without hypoalbuminemia; Clinical characteristics and response to angiotensin converting enzyme inhibition. Am J Kidney Dis 1991 17: 330-338.

44. Mogensen CE, Christensen CK. Predicting diabetic nephropathy in insulin-dependent patients. NEJM 1984: 311: 89-93

45. Viberti GC, Jarreut RJ, Mahmud U, Hill RD, Argyropoulos A, Keen H. Microalbuminuria as a predictor of clinical nephropathy in insulin-dependent diabetes mellitus. Lancet 1982; 1 : 1430-2.

46. Materson BJ. ACE inhibitors as a shield against diabetic nephropathy. Arch Int Med 1.996; 156: $239-240$

47. Ravid $M$, Lang R, Rachmani R, Lishner $M$. Long term renoprotective effect of angiotensin converting enzyme inhibition in NIDDM. Arch Int Med 1996; 156(2): 286-289.

48. Kasiske BL, Kalil RSN, Ma JZ, Liao M, Keane WF. Effects of antihypertensive therapy on the kidney in patients with diabetes: a meta-regression analysis. Ann Intern Med 1993; 1.18: 129-38. 49. Bakris GL. Angiolensin converting enzyme inhibitors and progression of diabetic nephropathy. Ann Intern Med 1993; 118: 643-4.

50. Zatz R, Dunn BR, Meyer TW; Anderson S, Rennke HG, Brenner BM. Prevention of diabetic glomerulopathy by pharmacological amelioration of glomerular capillary hypertension. J Clin Invest 1986; 77: 1925-1.930.

51. Anderson S, Rennke HG, Garcia DL, Brenner BM. Short- and long-term effects of antihypertensive therapy in the diabetic rat. Kidney Int 1989; 36: $526-536$

52. DeFronzo RA, Ferrannini E. Insulin resistance: a multifaceted syndrome responsible for NIDDM, obesity, hypertension, dyslipidemia, and other atherosclerotic cardiovascular diseases. Diabetes Care 1991; 14: 173-194.

53. DeFronzo RA. Incipient diabetic nephropathy: etiologic and therapeutic considerations. Pawling, NY: Caduceus, 1993, 1-30.

54. Keilani T, Schueter WA, Levin ML, Batlle DC. Improvement of lipid abnormalities associated with proteinuria using fosinopril, an angiotensinconverting enzyme inhibitor. Ann Intern Med 1993; 118(4): 246-254. 
55. Romero CJ, Raij L, Granger JP, Ruilope LM, Rodicio JL. Multiple effects of calcium entry blockers on renal function in hypertension. Hypertension 1.987; 10(2):140-151.

56. Hirsch Irl B. Surveillance for complications of diabetes: don't wait for symptoms before intervening. Postgrad Med 1996; 99(3): 147-163. 57. Cushman DW, Wang Fl, Fung WC, Harvey $\mathrm{CM}$, DeForrest JM. Differentiation of angiotensinconverting enzyme (ACE) inhibitors by their selective inhibition of ACE in physiologically important target organs. Am J Hypertens 1989; 2: 294-306.

58. Bakris GL, Barnhill B, Saddler R. Treatment of arterial hypertension in diabetic man: importance of therapeutic selection. Kidney Int 1992; 41 : 912-919.

59. Velussi M, Brocco E, Frigato F, et al. Effects of cilazapril and amlodipine on kidney function in hypertensive NIDDM patients. Diabetes 1996(Feb); 45(2): $216-222$.

60. Sarula I, Kanno Y, Hayashi K, Suzuki H. Renal effects of Amlodipine. J Human Hypertension 1995(Mar); 95(Suppl 1): 51 1.-516.

61. Ranieri G, Andriani A, Lamontanara G, De Cesaris R. Effects of lisinopril and amlodipine on microalbuminuria and renal function in patients with hypertension. Clin Pharmacol Therap 1994 Sept; 56(3): 323-330.

62. Dworken LD, Tolbert E, Recht PA, Hersch JC, Feiner $\mathrm{H}$, Levin RI. Effects of amlodipine on glomerular filtration, growh, and injury in experimental hypertension. Hypertension 1996(Feb); 27(2): 245-250.

63. DeQuattro V. Individualization of therapy for hypertension in the 1990's: the role of calcium antagonists. Clinical \& Experimental Hypertension 1994(Nov); 16(6): 853-864.

64. Reams GP. Do calcium channel blockers have renal protective effects? Drugs and Aging 1994(Oct); 263-287.

65. Hoelscher D, Bakris G. Antihypertensive therapy and progression diabetic renal disease. J Cardiovascular Pharmacology (1994); 23(Supp 1): $534-\$ 38$.

66. Jungmann E, Usadel KH. Renal long-term effects of calcium antagonist treatment in patients with diabetes mellitus. Clinical Investigator 1992(Oct); 70(10): 942-948.

67. Siewert-Delle A, Ljungman S, Hartford $M$, Wikstrand J. Effects of intensified blood-pressure reduction on renal function and albumin excre- tion in primary hypertension. Am J Hypertension 1995(Feb); 8(2): 113-123.

68. Herlitz $\mathrm{H}$. long-term effects of felodipine in patients with reduced renal function. Kidney International 1992(May); 36 (Suppl): S110-113.

69. Elmfeldt D, Nordlander M, Edgar B. Renal effects of felodipine-A review. Kidney International 1992(May); 36(Suppl1): S54-S60

70. Ferder L, Daccordi HA, Martello M, Marisa P, Inserra $F$ ACE inhibitors versus calcium antagonists in the treatment of diabetic hypertensive patients. Hypertension 1992; 19(Suppl 2): 237-42. 71. Rodicio JL, Morales JM, Alcazar JM, Ruilope I.M. Calcium antagonists and renal protection. J Hypertension 1993(Mar); 1 l(Suppl 1): S49-S53. 72. Norgaard K, Jensen T, Feldt-Rasmusen B. Effects of isradipine in type I (insulin-dependent) diabetic patients with albuminuria and normal blood pressure. J Human Hyperiension 1992(Apr); 6(2): 1.45-150.

73. Blecker $D$. Antihypertensive therapy with isradipine in patients with special salety concerns. Angiology 1994(Dec); 45(12): 997-1008.

74. Norgaard K, Jensen T, Feldt-Rasmussen B, et al. Comparison of spiralipril and isradipine SRO in patients with hypertension and diabetes. In: Programme and abstracis of the 14 th scientific meeting of the international society of hypertension; Madrid, Spain: 1992 June 14-1.6.

75. Ohno $A$, Inagaki $C$, Honda $K$, Sugino $N$. Comparison of converting enzyme inhibitors and calcium channel blockers in SHR with nephrotoxic serum nephritis. Japanese Journal of Nephropathy 1992(Apr); 34(4): 405-410

76. Massey SG. Nephrology. JAMA 1995(Jun); 273(21): 1693-1695.

77. Liori HH, Huang TP, Campese VM. Effects of long-term therapy with captopril on proteinuria and renal function in patients with non- insulin dependent diabetes and non -diabetic renal diseases. Nephron 1995; 69(1): 41-48.

78. Crepaldi G, Carraro A, Brocco E, el.al.. Hypertension and non- insulin dependent diabetes: A comparison between an angiotensin converting enzyme inhibitor and a calcium antagonist. Acta Diabetologica 1995(Oct); 32(3): 203-208.

79. Howes LG. Critical assessment of ACE inhibitors- Part 2. Australian Family Physician 1995(Apr); 24(4): 639, 641-643.

80. O'Donnell MJ, Rowe BR, Lawson N, Horton A, Gyde OH, Barnell AH. Placebo-controlled trial of lisinopril in normotensive diabetic patients with incipient nephropathy. J Human Hypertension 1993(Aug); 7(4): 327-332.

81. Melchoir WR, Bindlish V, Jaber LA. Angiotensin-converting enzyme inhibitor in diabetic nephropathy. J Human Hypertension 1993(Mar); 27(3): 344-350.

82. Sano T, Hotla N, Kawamura T, eL.al. Effects of long-term enalapril treatment on persistent microalbuminuria in normotensive lype 2 diabetic patients: results of a 4-year, prospective, randomized study. Diabetic Medicine 1996(Feb); 13(2): 120-124.

83. Trevisan $R$, Tiengo A. Effects of low-dose ramipril on microalbuminuria in normotensive or mild hypertensive non insulin dependent diabetic patients. North-East Italy Microalbuminuria Study Group. Am J Hypertension 1.995(Sept); 8(9): 876883.

84. The Grande Roche ACE debate. South African Medical Journal 1994(Feb); Suppl: 1-4.

85. Dominguez LJ, Barbagallo M, Katıah W, Garcia D, Sowers JR. Quinapril reduces microalbuminurialn essential hypertensive and in diabetic hypertensive subjects. Am J hypentension 1995(Aug); 8(8): 808-8.14.

86. Manzato F, Capurso A, Crepaldi G. Modification of cardiovascular risk factors during antihypertensive treatment : A multicentre trial with quinapril. J International Med Research 1993(Jan/Feb); 2 I(1): 15-25.

87. Vranes D, Dilley RJ, Cooper ME. Vascular changes in the diabetic kidney: Effects of $A C E$ inhibition. J Diabetes and Its Complications 1995(Oct/Dec); 9(4): 296-300

88. Diabetes surveillance 1993. Atlanta: Centers for Disease Control and Prevention: US Department of Health and Human Services, National Center for Chronic Disease Prevention; 1993 Nov. 89. Clark CM Jr, Lee DA. Prevention and treatment of the complications of diabetes mellitus. $\mathrm{N}$ Engl J Med 1995; 332(18): 1210-17.

90. Kidney Disease Foundation Website July 1997@http:/www.kdt.org.sg/select-right.htm 91. American Kidney Fund Website July 1997@ hup:// ww.arbon.com/kidney/donate.hum 92. American Health Care Network Pricing with Medispan July 1.997.

93. Kidney Disease Foundation Website July 1997@ http:/www.kdt.org.sg/know-right.hım 94. Health Watch: Methodist Health Care System Website July 1997@ http://methodisthealth.com/ health/diabetes/complic.htm. 